\title{
ANALISIS PENDAPATAN NELAYAN JARING INSANG (GILL NET) DI DESA PANIPAHAN TELUK PULAI KECAMATAN PASIR LIMAU KAPAS KABUPATEN ROKAN HILIR
}

\author{
Income Analysis of Gill Net Fishermen in Panipahan Teluk Pulai Village, Pasir Limau \\ Kapas District, Rokan Hilir Regency
}

\author{
Tibrani \\ Dosen Prodi Agribisnis, Universitas Islam Riau \\ Email: tibranikarimi@agr.uir.ac.id \\ [Diterima: November 2021; Disetujui: Desember 2021]
}

\begin{abstract}
This study aims to identify and analyze the characteristics and business profile of gill net fishermen, gill net fishing technology, and catching costs and income of gillnet fishermen in Panipahan Teluk Pulai Village, Pasir Limau Kapas District, Rokan Hilir Regency. This study used a survey method for gill net fishermen. Data collection was carried out by census from 15 fishermen and consisted of primary data and secondary data. The data was analyzed by using descriptive qualitative and quantitative analyses. The results showed that the average age of fishermen was 34.8 years, the education level of fishermen was 7.4 years, the length of business experience was 12.26 years, and the number of family was 3 people. The business profile in the form of a business is an individual business and the business scale is a micro business. The fishing technology used a motorboat with an engine power of 6-7 Gt, the operation was carried out by the owner fisherman with 4 crew members. The gill nets were used with a mesh size of 3.5 inches and a net length of $1,320 \mathrm{~m}$. The average cost of production/capture of gillnet fishermen was IDR 2,408,800 for variable costs, IDR 261,060 for fixed costs, and IDR 1,839,895 for crew members. The income of fishermen who own gill nets was IDR 7,269,598/trip and the profit of owner fishermen was IDR 2,759,843/trip. The value of the $\mathrm{R} / \mathrm{C}$ ratio was 1.6 , indicating that the fishing businesses were feasible because the RCR value was more than 1 and the production BEP of gillnet fishermen was $203,316 \mathrm{~kg}$. It means that gill net fishermen must produce 203,316 kg for return on investment and BEP Price is IDR 13,760. It means that gill net fishermen have to sell their catch at a price of IDR 13,760 for returning of investment.
\end{abstract}

Keywords: Income, Fishermen, Fishing Technology, Gill Nets

\begin{abstract}
ABSTRAK
Penelitian ini bertujuan untuk mengetahui dan menganalisis karakteristik dan profil usaha nelayan jaring insang, teknologi penangkapan ikan dengan jaring insang, dan biaya penangkapan dan pendapatan nelayan jaring insang di Desa Panipahan Teluk Pulai Kecamatan Pasir Limau Kapas Kabupaten Rokan Hilir. Penelitian ini menggunakan metode survey terhadap nelayan jaring insang di Desa Panipahan Teluk Pulai Kecamatan Pasir Limau Kapas Kabupaten Rokan Hilir. Pengumpulan data dilakukan secara sensus sebanyak 15 orang nelayan. Data yang dikumpulkan terdiri dari data primer dan data skunder. Metode analisis adalah analisis deskriptif kualitatif dan kuantitatif. Hasil penelitian menunjukkan bahwa rata-rata umur nelayan 34,8 tahun, tingkat pendidikan nelayan 7,4 tahun, lama pengalaman berusaha 12,26 tahun dan jumlah tanggungan keluarga adalah 3 orang. Profil usaha dalam bentuk usaha perseorangan dan skala usaha adalah usaha mikro. Teknologi penangkapan menggunakan kapal motor dengan kekuatan mesin 6-7 Gt, pengoperasian dilakukan oleh nelayan pemilik dengan 4 ABK. Jaring insang yang digunakan dengan ukuran mata jaring (mesh size) 3,5 inc dan panjang jaring $1320 \mathrm{~m}$. Rata-rata biaya produksi/penangkapan nelayan jaring insang yaitu biaya variabel Rp 2.408.800, biaya tetap Rp 261.060 dan ABK Rp 1.839.895, penerimaan Rp 7.269.598/ trip dan keuntungan $\mathrm{Rp}$ 2.759.843/trip. Nilai R/C ratio usaha penangkapan dengan alat tangkap jaring insang yaitu 1,6, menunjukan usaha penangkapan layak dijalankan karena memperoleh nilai RCR lebih dari 1. BEP produksi adalah 203,316 kg yang artinya nelayan jaring insang harus menghasilkan
\end{abstract}


203,316 kg untuk balik modal dan BEP harga adalah Rp 13.760 yang artinya nelayan jaring insang harus menjual hasil tangkapannya dengan harga Rp 13.760 untuk balik modal.

Kata kunci: Pendapatan, nelayan, teknologi penangkapan, jaring insang.

\section{PENDAHULUAN}

Indonesia merupakan sebuah negara kepulauan yang terdiri dari belasan ribu pulau dengan penduduk pantai yang besar jumlahnya. Kenyataan ini memungkinkan timbulnya struktur kehidupan perairan yang memunculkan permukiman-permukiman penduduk di sekitar garis pantai. Dalam hal ini, untuk memenuhi kebutuhan hidupnya sehari hari para penduduk yang bermukim di daerah pantai tersebut pada umumnya memilih pekerjaan sebagai nelayan selain pekerjaanpekerjaan sampingan lainnya. Sumber daya pada sektor perikanan merupakan salah satu sumberdaya yang penting bagi hidup masyarakat khususnya di pemukiman penduduk di sekitar garis pantai.

Sumber daya perikanan dapat dimanfaatkan untuk meningkatkan taraf hidup dan kesejahteraan nelayan, hingga mampu memenuhi kebutuhan dasar untuk kehidupannya. Namun kenyataannya masih banyak nelayan yang belum bisa meningkatkan hasil pendapatannya dikarenakan berbagai faktor yaitu, modal kerja, pengalaman kerja yang dimiliki dan sebagainya. Pendapatan nelayan tidak dapat di prediksikan seperti pendapatan pedagang atau petani karena pendapatan nelayan merupakan pekerjaan yang tidak pasti.

Produksi perikanan di Provinsi Riau sebagian besar berasal dari perikanan laut. Data yang bersumber dari BPS Provinsi Riau menunjukan bahwa pada tahun 2019, dari sejumlah 138.531 ton total produksi ikan tangkap, sebanyak 111.714 ton merupakan hasil perikanan tangkap laut.

Dinas Perikanan Kabupaten Rokan Hilir sejak awal berdirinya menyadari bahwa Kabupaten Rokan Hilir merupakan daerah yang memiliki potensi untuk berkembangnya produksi, pengolahan dan pemasaran hasil perikanan. Selain itu secara historis kabupaten ini merupakan penghasil ikan terbesar, hasil ekspor komoditi ikan yang berasal dari wilayah perairan yang cukup luas memegang peranan penting dalam meningkatkan pendapatan masyarakat (Dinas Perikanan Kabupaten Rokan Hilir 2020). Data produksi perikanan tangkap laut di Kabupaten Rokan Hilir 20152018 dapat dilihat pada Tabel 1.

Tabel 1. Produksi Perikanan Tangkap Laut di Kabupaten Rokan Hilir 2015-2019

\begin{tabular}{ccrr}
\hline Tahun & $\begin{array}{c}\text { Produksi } \\
\text { (Ton) }\end{array}$ & $\begin{array}{c}\text { Peningkatan } \\
\text { (ton) }\end{array}$ & $\begin{array}{c}\text { Persentase } \\
(\%)\end{array}$ \\
\hline 2015 & $51.101,5$ & - & - \\
2016 & $53.421,9$ & $2.320,4$ & 4,5 \\
2017 & $45.797,7$ & $-7.624,2$ & $-14,0$ \\
2018 & $51.355,83$ & $5.558,13$ & 12,0 \\
2019 & 51.942 & 586,17 & 1,1 \\
\hline Sumber: BPS Provinsi Riau 2020 &
\end{tabular}

Tabel 1. Menunjukkan bahwa produksi perikanan tangkap laut di Kabupaten Rokan Hilir dari tahun 2015-2016 mengalami peningkatan produksi sebesar 2.320,4 ton atau 4,5\%, produksi perikanan tangkap laut pada tahun 2016-2017 mengalami penurunan produksi sebesar 7.624,2 ton atau $-14 \%$ dan produksi perikanan tangkap laut pada tahun 2017-2018 mengalami peningkatan sebesar $5.558,13$ ton atau $12 \%$, sedangkan produksi perikanan tangkap laut pada tahun 2018-2019 mengalami peningkatan sebesar 586,17 ton atau $1,1 \%$.

Kabupaten Rokan Hilir merupakan salah satu daerah yang mempunyai potensi dalam perikanan tangkap laut, produksi perikanan tangkap laut di Kabupaten Rokan Hilir menempati urutan pertama berdasarkan Kabupaten/kota di Provinsi Riau pada tahun 2019.

Kelompok masyarakat yang memanfaatkan sumber daya perikanan adalah masyarakat nelayan. Masyarakat nelayan merupakan kelompok masyarakat yang melakukan aktivitas usaha dengan mendapat penghasilan bersumber dari kegiatan menangkap ikan. Semakin banyak tangkapan maka semakin besar pula pendapatan yang diterima dan pendapatan tersebut sebagian besar untuk keperluan konsumsi keluarga. Dengan demikian tingkat pemenuhan kebutuhan konsumsi keluarga ditentukan oleh pendapatan yang diterimanya. Sumber daya perikanan sebenarnya secara potensial dapat dimanfaatkan untuk meningkatkan taraf hidup dan kesejahteraan nelayan, namun pada kenyataannya masih banyak nelayan belum dapat meningkatkan hasil tangkapannya, 
sehingga tingkat pendapatan nelayan tidak meningkat (Sujarno 2008).

Teori dasar ekonomi menyatakan bahwa pada barang normal harga suatu komoditas dan kuantitas yang akan diminta berhubungan secara negatif, dengan faktor lain tetap sama. Jadi dengan kata lain, semakin rendah harga ikan, maka jumlah yang diminta akan semakin besar, dan semakin tinggi harga semakin rendah jumlah yang diminta. Apabila terjadi kenaikan harga barang substitusi ikan konsumen akan tetap mengkonsumsi ikan dan permintaan akan ikan pun meningkat. Apabila terjadi kenaikan pendapatan dan jumlah penduduk, maka permintaan ikan pun akan meningkat. Dalam hal selera masyarakat, semakin banyak masyarakat yang menyukai ikan, baik karena alasan kesehatan maupun karena alasan rasa ikan yang enak dan gurih, maka permintaan akan ikan pun akan meningkat (Tuwo,2011). Data Produksi perikanan tangkap laut menurut Kecamatan di Kabupaten Rokan hilir dapat dilihat pada tabel 2.

Tabel 2. Produksi Perikanan Tangkap Laut berdasarkan Kecamatan di Kabupaten Rokan Hilir, 2019

\begin{tabular}{clcc}
\hline No & Kecamatan & $\begin{array}{c}\text { Perikanan laut } \\
\text { (ton) }\end{array}$ & $\begin{array}{c}\text { Persentase } \\
(\%)\end{array}$ \\
\hline 1 & Kubu & 166,00 & 0,31 \\
2 & Bangko & $11.520,00$ & 22,20 \\
3 & Pasir Limau & $21.985,00$ & 42,00 \\
& Kapas & & \\
4 & Sinaboi & $8.967,77$ & 17,00 \\
5 & Pekaitan & 18,23 & 0,04 \\
6 & Kubu & $9.285,00$ & 18,00 \\
& Babussalam & & \\
& Jumlah & $51.942,00$ & 100,00 \\
\hline
\end{tabular}

Sumber : Dinas Perikanan dan Kelautan Kabupaten Rokan Hilir 2020

Berdasarkan Tabel 2. Dapat dilihat terdapat beberapa Kecamatan sebagai daerah produksi perikanan tangkap laut di Kabupaten Rokan Hilir. Dari beberapa Kecamatan tersebut Kecamatan Pasir Limau Kapas merupakan penghasilan ikan terbanyak dan terdapat pada urutan pertama yaitu sebesar $21.985,00$ ton atau $42 \%$. Selanjutnya urutan kedua diikuti oleh Kecamatan Bangko yaitu sebesar 11.520,00 ton atau 22,2\%. Urutan ketiga adalah Kecamatan Kubu Babussalam yaitu sebesar 9.285,00 ton atau $18 \%$. Pada urutan terakhir terdapat pada Kecamatan Pekaitan yaitu sebesar 18,23 ton atau $0,04 \%$.
Hasil produksi perikanan di Kecamatan Pasir Limau Kapas akan langsung di pasarkan melalui pedagang pengumpul, pedagang besar, pedagang pengecer, maupun langsung kekonsumen mengingat bahwa sifat hasil perikanan yang mudah rusak dan harus memerlukan penanganan khusus untuk mempertahankan mutu hingga sampainya ke komsumen.

Komoditi ikan yang cepat membusuk/rusak apabila disimpan dalam waktu yang lama, oleh karena itu, untuk menjaga ikan agar tetap segar, nelayan Kecamatan Pasir Limau kapas mengawetkan ikan yang sudah ditangkap dengan cara menggunakan es yang secukupnya.

Pada umumnya masyarakat di Kecamatan Pasir Limau Kapas bermata pencaharian sebagai nelayan dan pekerjaan ini merupakan salah satu pekerjaan yang diandalkan oleh masyarakat tersebut, karena daerah ini merupakan daerah yang potensial dalam menghasilkan ikan, dan Kecamatan Pasir Limau Kapas merupakan penghasilan produksi perikanan tangkap laut tertinggi di Kabupaten Rokan Hilir pada tahun 2019.

Kecamatan Pasir Limau Kapas memiliki beberapa kelurahan/desa salah satunya Panipahan Teluk Pulai dengan penduduk 7.739 jiwa yang masyarakatnya sebagian besar merupakan nelayan tangkap laut. Panipahan memiliki potensi perikanan tangkap yang besar, laut lepas selat melaka ini sejak dulu memiliki potensi alam yang kaya dengan berbagai jenis ikan, udang, kerang dan lain sebagainya. Panipahan merupakan kelurahan/kota yang letaknya berjauhan dari ibukota bagansiapi-api, untuk mencapai kota panipahan tersebut masyarakat harus menempuh jarak antara 1,5 jam hingga 2 jam dengan menggunakan speedboat.

Panipahan dijuluki kota diatas laut, mungkin karena ribuan rumah dikota ini ditopang oleh puluhan kayu penyangga sebagai pondasi pada setiap rumah dengan tinggi kayu tiga meter sampai enam meter tergantung keberadaannya ditengah laut atau dipinggir pantai. Masyarakat disini pada umumnya mata pencahariannya adalah sebagai nelayan.

Alat tangkap ikan yang digunakan di Kabupaten Rokan Hilir jika dilihat dari cara beroperasinya alat tersebut dibedakan menjadi dua golongan yaitu alat tangkap statis dan alat tangkap dinamis. Alat tangkap statis adalah alat tangkap yang sifatnya tetap atau tidak 
berpindah pindah dalam rentang waktu yang relatif lama, alat tangkap jenis ini yang ada di Kabupaten Rokan Hilir adalah bubu tiang. Alat tangkap dinamis memiliki sifat yang berlawanan dengan alat tangkap statis, bila alat tangkap statis sifatnya tetap atau tidak berpindah pindah maka alat tangkap dinamis sifatnya selalu bergerak atau berpindah pindah. Alat tangkap yang ada di Kabupaten Rokan Hilir sebagian besar adalah alat tangkap dinamis dan di antara alat tangkap dinamis tersebut yang paling banyak digunakan adalah jaring insang (gillnet). Daerah penangkapan atau tempat beroperasinya alat tangkap tersebut sejauh 12 mil dari garis pantai (Dinas perikanan kabupaten rokan hilir 2017).

Menurut Sparre dan Venema (1992) ada empat cara tertangkapnya ikan oleh jaring insang, yaitu 1) tertangkap secara terjerat tepat di belakang mata (snagged), 2) terjerat di belakang tutup insang (gilled), 3) terjerat di depan sirip punggung (wedged), dan 4) ikan terbelit akibat bagian tubuh yang menonjol (gigi, rahang, sirip) tanpa harus menerobos mata jaring (entangled).

Produksi perikanan di Kecamatan Pasir Limau Kapas yaitu sebesar 21.985 ton dan meliliki laut yang sangat luas, namun kenyataannya nelayan jaring insang di Desa Panipahan Teluk Pulai tersebut belum sejahtera.

Kecamatan Pasir Limau Kapas menghasilkan produksi perikanan tangkap laut sebesar 21.985,00 ton pada tahun 2019. Khusus nya di Panipahan Teluk Pulai merupakan sebagian besar mata pencahariannya adalah sebagai nelayan. Hal inilah yang mendorong peneliti untuk melakukan penelitian mengenai "Analisis Pendapatan Nelayan Jaring Insang (Gill Net) di Panipahan Teluk Pulai Kecamatan Pasir Limau Kapas Kabupaten Rokan Hilir"

Tujuan penelitian ini adalah untuk mengetahui dan menganalisis 1) Karakteristik dan Profil usaha nelayan jaring insang di Desa Panipahan Teluk Pulai Kecamatan Pasir Limau Kapas, 2) Teknologi penangkapan ikan nelayan jaring insang (Gill net) di Desa Panipahan Teluk Pulai Kecamatan Pasir Limau Kapas Kabupaten Rokan Hilirdan 3) Biaya Produksi, Pendapatan Kotor, Pendapatan Bersih, Efisiensi dan BEP alat tangkap Jaring Insang di Desa Panipahan Teluk Pulai Kecamatan Pasir Limau Kapas.

\section{METODE PENELITIAN}

Penelitian ini menggunakan metode survei terhadap usaha penangkapan ikan nelayan jaring insang di Desa Panipahan Teluk pulai Kecamatan Pasir Limau Kapas. Populasi dalam penelitian ini adalah seluruh nelayan jaring insang yang ada di Desa Panipahan Teluk Pulai Kecamatan Pasir Limau Kapas. Pengumpulan data dilakukan secara sensus dari 15 orang yang mengoperasikan alat tangkap jarring insang di daerah penelitian. Data yang dikumpulkan terdiri dari data primer dan data sekunder. Data primer yang dikumpulkan adalah karakteristik nelayan, profil usaha, teknologi penangkapan, biayabiaya, hasil tangkapan dan harga jual. Data sekunder di peroleh dari pihak lain yang terkait dalam penelitian ini seperti BPS Riau, BPS Rokan Hilir, Dinas Perikanan dan Kelautan Kecamatan Pasir Limau Kapas, Kantor Kepala Desa Panipahan Teluk Pulai dan buku-buku yang terkait dengan topik penelitian.

\section{Analisis Data}

Data yang sudah dikumpulkan dilapangan akan dikelompokkan sesuai jenisnya yaitu diskriptif kualitatif dan kuantitatif diuraikan dalam bentuk tabel dan gambar kemudian dianalisis sesuai tujuan penelitian dan dibahas berdasarkan data dan fakta yang ada dilapangan dan kemudian diambil suatu kesimpulan.

\section{Analisis Karakteristik dan Profil Usaha Nelayan}

Karakteristik dan profil usaha nelayan jaring insang dianalisis dengan menggunakan analisis deskriptif kualitatif yang meliputi: Umur, tingkat pendidikan, pengalaman berusaha, dan jumlah tanggungan keluarga dan Profil usaha meliputi: bentuk usaha dan skala usaha.

\section{Teknologi Penangkapan dengan Jaring Insang}

Teknologi penangkapan dengan jaring insang dianalisis menggunakan analisis deskriptif kualitatif yang meliputi : kapal, jaring insang dan lama operasi.

\section{Analisis Biaya Produksi dan Pendapatan Biaya Produksi}

Biaya produksi dalam penangkapan ikan adalah semua biaya yang dikeluarkan oleh nelayan selama satu trip. Biaya produksi terdiri dari biaya variabel dan biaya tetap. 
Maka total biaya dihitung dengan menggunakan rumus umum menurut Hernanto (1991) sebagai berikut :

$$
\begin{aligned}
& \mathrm{TC}=\mathrm{TVC}+\mathrm{TFC} \\
& \mathrm{TC}=\left(\mathrm{X}_{1} \cdot \mathrm{Px}_{1}\right)+\left(\mathrm{X}_{2} \cdot \mathrm{Px}_{2}\right)+\left(\mathrm{X}_{3} \cdot \mathrm{Px}_{3}\right)+\left(\mathrm{X}_{4} \cdot \mathrm{PX}_{4}\right) \\
& +\mathrm{D}
\end{aligned}
$$

Keterangan :

$$
\begin{aligned}
& \mathrm{TC}=\text { Total biaya (Rp/trip) } \\
& \mathrm{TVC}=\text { Total biaya variabel }(\mathrm{Rp} / \text { trip}) \\
& \mathrm{TFC}=\text { Total biaya tetap (Rp/trip) } \\
& \mathrm{X}_{1} \quad=\text { Pemeliharaan (pertrip) } \\
& \mathrm{Px}_{1}=\text { Harga pemeliharaan (Rp/unit) } \\
& \mathrm{X}_{2}=\mathrm{Bbm} \text { (ltr /trip) } \\
& \mathrm{Px}_{2}=\operatorname{Harga~bbm~(Rp/ltr)~} \\
& \mathrm{X}_{3} \quad=\text { Es batu (unit/trip) } \\
& \mathrm{Px}_{3} \quad=\text { Harga Es batu Rp/unit) } \\
& \mathrm{X}_{4} \quad=\text { Konsumsi (unit/trip) } \\
& \mathrm{Px}_{4} \quad=\text { Harga konsumsi perunit (Rp/unit) } \\
& \mathrm{D} \quad=\text { Penyusutan (Rp/unit/trip) } \\
& \mathrm{D}=\frac{\mathrm{C}-\mathrm{SV}}{\mathrm{UL}}
\end{aligned}
$$

Keterangan :

$\mathrm{D} \quad=$ Nilai penyusutan (Rp/unit)

$\mathrm{C}=$ Harga beli alat (Rp/unit)

$\mathrm{SV} \quad=$ Nilai sisa alat (Rp/unit)

$\mathrm{UL} \quad=$ Masa pakai alat (tahun)

\section{Pendapatan Kotor}

Menurut Soekartawi (1995) penerimaan/pendapatan kotor adalah hasil perkalian antara jumlah produksi dengan harga jual produk.

$\mathrm{TR}=\mathrm{Py} . \mathrm{Y}$.

Keterangan :

$$
\begin{array}{ll}
\mathrm{TR} & =\text { Total Penerimaan (revenue) } \\
\mathrm{Py} & =\text { Harga }(\mathrm{Rp} / \mathrm{Kg} \text { ikan laut }) \\
\mathrm{Y} & =\text { Total Produksi (ikan laut } / \mathrm{Kg} \text { ) }
\end{array}
$$

\section{Pendapatan Bersih}

$$
\text { Menurut Soekartawi }
$$

keuntungan dalam suatu usaha didapatkan dari perhitungan hasil pengurangan antara total biaya yang telah digunakan. Untuk mengetahui keuntungan nelayan jaring insang digunakan rumus sebagai berikut :

$$
\pi=\mathrm{TR}-\mathrm{TC}
$$

Keterangan :

$$
\begin{array}{ll}
\pi & =\text { Keuntungan (profit) } \\
\mathrm{TR} & =\text { Total Penerimaan (Total revenue) } \\
\mathrm{TC} & =\text { Total Biaya }
\end{array}
$$

\section{Efisiensi Usaha}

Untuk menghitung efisiensi usaha digunakan rumus :

$\mathrm{R} / \mathrm{C}=\frac{\mathrm{TR}}{\mathrm{TC}}$

Keterangan :

$\mathrm{RCR}=$ Ratio biaya dengan penerimaan

$\mathrm{TR}=$ Total Penerimaan (Total revenue)

$\mathrm{TC}=$ Total Biaya

Kriteria Keputusan :

$\mathrm{R} / \mathrm{C}>1$ : Usaha menguntungkan

$\mathrm{R} / \mathrm{C}=1$ : Usaha berada pada titik impas

$\mathrm{R} / \mathrm{C}<1$ : Usaha tidak menguntungkan

\section{Break Event Point (BEP)}

Menurut Soekartawi (2006), analisis BEP atau nilai impas adalah suatu teknis analisis untuk mempelajari hubungan antara biaya tetap, biaya variabel dan keuntungan. Volume penjualan BEP dalam penelitian merupakan pengukuran dimana kapasitas riil pengolahan bahan baku menjadi output menghasilkan total penerimaan yang sama dengan pengeluaran BEP dalam unit dan dalam rupiah yang dirumuskan sebagai berikut :

$$
\begin{aligned}
& \text { BEP Produksi }=\frac{\text { Total Biaya }}{\text { Harga Penjualan }} \\
& \text { BEP Harga }=\frac{\text { Total Biaya }}{\text { Total Produksi }} . . . . . .
\end{aligned}
$$

\section{HASIL DAN PEMBAHASAN}

\section{Karakteristik Nelayan Jaring Insang}

Karakteritik responden nelayan jaring insang (Gill Net) di Desa Panipahan Teluk Pulai Kecamatan Pasir Limau Kapas dikelompokkan berdasarkan umur, tingkat pendidikan, lama berusaha, dan jumlah tanggungan keluarga. Karakteristik nelayan Jaring insang dapat dilihat pada Tabel 3.

\section{Umur}

Umur mempengaruhi kemampuan nelayan dalam berusaha dan akan berpengaruh terhadap hasil kerja dan pendapatan nelayan. Nelayan jaring insang di Desa Panipahan Teluk Pulai Kecamatan Pasir Limau Kapas berdasarkan Tabel 3. Rata-rata umur nelayan jaring insang di Desa Panipahan Teluk Pulai adalah 34,8 tahun masih tergolong produktif dan diharapkan dapat meningkatkan pendapatan. 


\section{Tingkat Pendidikan}

Pendidikan sangat berpengaruh terutama dalam penerimaan inovasi teknologi yang relevan dan sesuai dalam meningkatkan pendapatan nelayan. Nelayan jaring insang di Desa Panipahan teluk Pulai berdasarkan Tabel 3 memiliki tingkat pendidikan rata-rata 7,4 yaitu setara dengan SMP dan sudah bisa menerima informasi, teknologi, dan inovasi yang relevan.

\section{Pengalaman Berusaha}

Semakin lama seorang menekuni pekerjaanya, maka semakin panjang pengalaman yang dimiliki dalam berbagai hal untuk meningkatkan pendapatannya. Berdasarkan Tabel 3 Pengalaman nelayan jaring insang sudah cukup lama yaitu rata-rata 12,26 tahun, maka sudah bisa dikatakan nelayan jaring insang memiliki pengalaman yg cukup lama.

Tabel 3. Karakteristik Nelayan Jaring Insang di Desa Panipahan Teluk Pulai Kecamatan Pasir Limau Kapas 2021

\begin{tabular}{|c|c|c|c|}
\hline No & $\begin{array}{l}\text { Umur } \\
\text { ( tahun) }\end{array}$ & $\begin{array}{l}\text { Jumlah } \\
\text { (jiwa) }\end{array}$ & $\begin{array}{l}\text { Persentase } \\
(\%)\end{array}$ \\
\hline \multirow[t]{6}{*}{1} & $26-30$ & 3 & 20,00 \\
\hline & $31-35$ & 4 & 26,66 \\
\hline & $36-40$ & 7 & 46,66 \\
\hline & $41-45$ & 1 & 6,66 \\
\hline & Jumlah & 15 & 100,00 \\
\hline & Rata-rata & 34,8 & \\
\hline \multirow[t]{6}{*}{2} & Tingkat Pendidikan (tahun) & & \\
\hline & 6 & 7 & 46,67 \\
\hline & 9 & 8 & 53,33 \\
\hline & 12 & - & \\
\hline & Jumlah & 15 & 100,00 \\
\hline & Rata-rata & 7,4 & \\
\hline \multirow[t]{8}{*}{3} & Pengalaman Berusaha (tahun) & & \\
\hline & 10 & 3 & 20,00 \\
\hline & 11 & 4 & 26,66 \\
\hline & 12 & 3 & 20,00 \\
\hline & 14 & 1 & 6,66 \\
\hline & 15 & 4 & 26,66 \\
\hline & Jumlah & 15 & 100,00 \\
\hline & Rata-rata & 12,26 & \\
\hline \multirow[t]{8}{*}{4} & Tanggungan Keluarga & & \\
\hline & 1 & 3 & 20,00 \\
\hline & 2 & 1 & 6,66 \\
\hline & 3 & 7 & 46,66 \\
\hline & 4 & 1 & 6,66 \\
\hline & 5 & 3 & 20,00 \\
\hline & Jumlah & 15 & 100,00 \\
\hline & Rata-rata & 3 & \\
\hline
\end{tabular}

\section{Jumlah Tanggungan Keluarga}

Jumlah tanggungan dapat mempengaruhi pendapatan nelayan jaring insang, Tabel 3. menunjukan tanggungan nelayan jaring insang di Desa Panipahan Teluk Pulai Kecamatan Pasir Limau Kapas yang paling banyak adalah 3 orang yaitu $46,66 \%$ dan yang memiliki tanggungan 1dan 5 orang yaitu $40,00 \%$, kemudian tanggungan yg paling sedikit adalah 2 dan 4 orang yaitu 13,32\%. Rata-rata tanggungan nelayan jaring insang di
Desa Panipahan Teluk Pulai Adalah 3 orang, semakin sedikit jumlah tanggungan keluarga maka semakin sedikit pengeluaran nelayan jaring insang.

\section{Profil Usaha}

Usaha nelayan jaring insang di Desa Panipahan Teluk Pulai Kecamatan Pasir Limau Kapas dijalankan oleh nelayan pemilik. Usaha ini merupakan usaha perseorangan, berbentuk usaha mikro yang bertujuan untuk mendapatkan hasil tangkapan dari penjualan produksi perikanan tangkap laut. 
Berdasarkan undang-undang Republik Indonesia nomor 20 tahun 2008 tentang usaha mikro, Kecil dan Menengah dengan kriteria sebagai berikut : 1) Usaha Mikro adalah memiliki kekayaan bersih paling banyak. Rp 50.000.000.-(lima puluh juta rupiah) diluar tanah dan bangunan tempat usaha dan memiliki hasil penjualan tahunan paling banyak Rp 300.000.000,-(tiga ratus juta rupiah). 2) Usaha Kecil adalah memiliki kekayaan bersih lebih dari Rp 50.000.000,(lima puluh juta rupiah) sampai $\mathrm{Rp}$ 500.000.000,-(lima ratus juta rupiah) diluar tanah dan bangunan dan memiliki hasil penjualan tahunan lebih dari Rp 300.000.000,(tiga ratus juta rupiah) sampai Rp 2.500.000.000,-(dua milyar lima ratus juta rupiah) dan 3) Usaha Menengah adalah memiliki kekayaan bersih lebih dari $\mathrm{Rp}$ 500.000.000,-(lima ratus juta rupiah) sampai Rp 10.000.000.000,-(sepuluh milyar rupiah) diluar tanah dan bangunan dan memiliki hasil penjualan tahunan lebih dari $\mathrm{Rp}$ 2.500.000.000,-(dua milyar lima ratus juta rupiah) sampai Rp 50.000.000.000,-(lima puluh milyar rupiah). Selain itu skala usaha juga ditentukan dari kriteria jumlah tenaga kerja, skala usaha mikro menggunakan tenaga kerja 1 sampai 4 orang. Usah Kecil menggunakan tenaga kerja 5 sampai 19 0rang sedangkan untuk usaha menengah menggunakan tenaga kerja 20 sampai 99 orang.

Tabel 4. Nilai dan Penyusutan alat Nelayan Jaring Insang di Desa Panipahan Teluk Pulai Kecamatan Pasir Limau Kapas, tahun 2021

\begin{tabular}{clcrrr}
\hline No & \multicolumn{1}{c}{ Nama } & Jumlah & \multicolumn{1}{c}{ Harga } & \multicolumn{1}{c}{ Nilai } & Penyusutan \\
\hline 1 & Kapal Motor (unit) & 1 & 60.733 .000 & 60.733 .000 & 33.734 \\
2 & Mesin (unit) & 1 & 11.000 .000 & 11.000 .000 & 36.666 \\
3 & Jaring Insang (bal) & 66 & 650.000 & 42.900 .000 & 142.999 \\
4 & Pelampung (unit) & 3.300 & 700 & 2.310 .000 & 7.699 \\
5 & Pemberat (kg) & 99 & 47.000 & 4.653 .000 & 15.510 \\
6 & Tali Ris Atas (kg) & 32 & 45.000 & 1.440 .000 & 4.800 \\
7 & TaliRis Bawah (kg) & 6,40 & 45.000 & 288.000 & 960 \\
8 & Tali (gulung) & 10 & 10.000 & 100.000 & 1.666 \\
9 & Cuban (unit) & 10 & 5.000 & 50.000 & 834 \\
10 & Fiber/ peti Es (unit) & 2,66 & 800.000 & 2.128 .000 & 7.111 \\
11 & Kompor (unit) & 1 & 250.000 & 250.000 & 833 \\
12 & Tabung Gas (unit) & 1 & 150.000 & 150.000 & 500 \\
13 & Periuk Nasi (unit) & 1 & 250.000 & 250.000 & 4.166 \\
14 & Sutil (unit) & 2 & 15.000 & 30.000 & 500 \\
15 & Wajan (unit) & 1 & 50.000 & 50.000 & 833 \\
16 & Jerigen (unit) & 2 & 45.000 & 90.000 & 1.500 \\
17 & Cangkir Plastik (unit) & 5 & 5.000 & 25.000 & 416 \\
18 & Piring Plastik (unit) & 5 & 4.000 & 20.000 & 333 \\
\hline & & Jumlah & & & 261.060 \\
\hline
\end{tabular}
bersih awal yang dimiliki nelayan jaring insang adalah dibawah 50.000.000,- dengan penjualan tahunan Rp 261.705.528 yang berarti masih dibawah Rp 300.000.000.- dan kriteria berdasarkan tenaga kerja nelayan jaring insang di Desa Panipahan Teluk Pulai memiliki tenaga kerja yaitu 4 orang. Dari kriteria tersebut maka skala usaha nelayan jaring insang adalah skala usaha mikro.

\section{Teknologi Penangkapan Ikan Dengan Jaring Insang}

Kapal

Kapal motor yang digunakan nelayan jaring insang di Desa Panipahan Teluk Pulai Kecamatan Pasir Limau Kapas memiliki ukuran 5-7 GT dan menggunakan mesin yang memiliki kemampuan berlayar dalam kondisi apapun dan layak untuk melaut.

\section{Jaring (Jaring Insang)}

Jaring insang yang digunakan nelayan Desa Panipahan Teluk Pulai yaitu dengan ukuran mata jaring (mesh size) 3,5 inc dan Panjang jaring rata-rata 66 bal $(20 \mathrm{~m} / \mathrm{bal})$ dengan pelampung rata-rata 3300 unit (50 unit/bal) dan pemberat rata-rata $99 \mathrm{~kg}$ $(1,5 \mathrm{~kg} / \mathrm{bal})$.dengan panjang tali ris atas dan tali ris bawah rata-rata $1.408 \mathrm{~m}$. Distribusi penggunaan dan penyusutan alat dapat dilihat pada Tabel 4. 
Dari Tabel 4. Dapat dilihat penggunaan alat pada nelayan jaring insang salah satunya adalah jaring insang dan kontruksi pada jaring insang dan jumlah Penyusutan alat yaitu sebesar Rp 261.060.

\section{Lama Operasi}

Pengoperasian dilakukan dengan jarak tempuh 15 mil kemudian jaring insang disiapkan dan di pisahkan antara pelampung dan pemberat agar dalam pengoperasian mudah dilakukan. Jaring insang tersebut di turunkan kelaut perlahan-lahan dengan cara dihanyutkan yang dilakukan oleh 4 anak buah kapal $(\mathrm{ABK})$. Jaring insang dibiarkan hanyut terbawa arus, ikan yang akan lewat melalui jaring tersebut akan terjerat pada insang atau terpuntal. Penurunan jaring di lakukan selama 3 jam baru kemudian jaring tersebut diangkat /tarik kedalam kapal, ikan yang terjerat jaring langsung dibuka/diambil dan dikumpulkan. Ikan yang telah dikumpulkan kemudian dimasukkan kedalam peti es. Pekerjaan seperti ini dilakukan setiap 9 jam/hari selama 3 hari. Setelah pulang ikan kemudian di jual di tempat penampungan ikan. Setelah pulang jaring kemudian di cuci dan dinaikan kekapal dan yang rusak kemudian di perbaiki untuk persiapan pemberangkatan selanjutnya.

\section{Biaya Produksi dan Pendapatan Nelayan Jaring Insang}

Biaya produksi/ penangkapan dalam penelitian ini adalah total biaya yang dikeluarkan oleh nelayan dalam pengoperasian jaring insang, total biaya meliputi biaya variabel (biaya operasional dan pemeliharaan), upah ABK dan biaya tetap (biaya penyusutan) yang dinyatakan dalam rupiah. Total biaya dalam pengoperasian jaring insang dapat dilihat pada Tabel 5.

Berdasarkan Tabel 5. Menunjukan bahwa biaya variabel terbesar dalam pengoperasian jaring insang adalah biaya operasional yaitu bbm sebesar Rp 671.000/trip atau 27\%, Es batu sebesar Rp 135.000 atau 5,5\%, dan konsumsi Rp 917.800 atau 38\%. kemudian biaya pemeliharaan yaitu jaring insang sebesar $\mathrm{Rp} 650.000$ atau $26 \%$, tali pengikat sebesar Rp 20.000 atau $0,83 \%$ dan solar Rp 15.000 atau 0,62\%. Kemudian biaya tetap yang merupakan biaya yang besarnya tidak di pengaruhi oleh jumlah produksi. Biaya tetap dalam usaha jaring insang yaitu biaya penyusutan sebesar Rp 261.060/trip dan biaya ABK sebesar 1.839.895/ trip.

Total biaya adalah semua biaya yang di keluarkan nelayan dalam usaha jaring insang yaitu meliputi total biaya variabel, total biaya tetap dan upah ABK. Total biaya nelayan jaring insang di Desa Panipahan teluk pulai adalah sebesar Rp 4.509.755/trip.

Pendapatan nelayan jaring insang meliputi : penerimaan dan keuntungan yang merupakan penjualan hasil penangkapan ikan nelayan jaring insang. Penerimaan dan keuntungan yang diterima oleh nelayan tergantung pada banyaknya hasil tangkapan.

Tabel 5. Analisis Usaha Nelayan Jaring Insang di Desa Panipahan Teluk Pulai Kecamatan Pasir Limau Kapas, Tahun 2021.

\begin{tabular}{|c|c|c|c|c|}
\hline No & Uraian & Jumlah (Unit) & Harga (Rp.) & Nilai (Rp.) \\
\hline $\mathrm{A}$ & Penerimaan & & & 7.269 .598 \\
\hline \multirow[t]{10}{*}{ B } & Biaya Variabel & & & \\
\hline & Biaya Pemeliharaan & & & \\
\hline & 1. Jaring insang(bal) & 1 & 650.000 & 650.000 \\
\hline & Tali pengikat (gulung) & 2 & 10.000 & 20.000 \\
\hline & Solar (ltr) & 2 & 7.500 & 15.000 \\
\hline & Biaya Operasional & & & \\
\hline & Solar (ltr) & 89 & 7.500 & 671.000 \\
\hline & Es batu (batang) & 54 & 2.500 & 135.000 \\
\hline & Konsumsi (hari) & 3 & & 917.800 \\
\hline & Total biaya variabel & & & 2.408 .800 \\
\hline \multirow[t]{2}{*}{$\mathrm{C}$} & Biaya Tetap & & & \\
\hline & Biaya penyusutan & & & 261.060 \\
\hline $\mathrm{D}$ & Nelayan ABK & & & 1.839 .895 \\
\hline $\mathrm{E}$ & Total Biaya & & & 4.509 .755 \\
\hline $\mathrm{F}$ & Produksi (kg) & 327,745 & 22,181 & 7.269 .598 \\
\hline \multirow[t]{2}{*}{ G } & Keuntungan & & & 4.599 .738 \\
\hline & Nelayan pemilik & & & 2.759 .843 \\
\hline
\end{tabular}




\section{Pendapatan Kotor/Penerimaan}

Penerimaan nelayan adalah besarnya jumlah produksi tangkapan yang dihasilkan dan dikalikan dengan harga yang berlaku dipasar. Penerimaan nelayan selalu berbeda setiap harinya tergantung pada jenis ikan dan jumlah ikan di hasilkan serta harga ikan yang berlaku di pasaran. Rata-rata penerimaan yang di peroleh nelayan jaring insang di Desa Panipahan Teluk Pulai Kecamatan Pasir Limau Kapas adalah sebesar Rp 7.269.598/trip dapat dilihat pada Tabel 15.

\section{Pendapatan Bersih/Keuntungan}

Keuntungan nelayan adalah selisih antara penerimaan dan total biaya yang di kelurkan. Setelah di kurangi dengan total biaya, hasil keuntungan dibagikan kepada nelayan pemilik yang pengoperasi sebesar 60 persen dan 40 persen lagi dibagikan dengan banyaknya $\mathrm{ABK}$ yang ikut pada pengoperasi penangkapan ikan nelayan jaring insang dalam setiap armada penangkapan.

Keuntungan yang diperoleh nelayan pemilik dan pengoperasi jaring insang di Desa Panipahan Teluk Pulai setelah di bagi dengan jumlah ABK yang ikut serta dalam operasi penangkapan adalah sebesar Rp 2.759.843/trip.

\section{Efisiensi /Return Cost Ratio (RCR)}

Berdasarkan dari perhitungan rumus besarnya R/C Ratio nelayan jaring insang sebelum dibagi dengan $\mathrm{ABK}$ adalah sebesar 2,7 dan $\mathrm{R} / \mathrm{C}$ ratio setelah dibagi dengan $\mathrm{ABK}$ adalah sebesar 1,6 dapat dilihat pada Tabel 6 .

Tabel 6. Jumlah RCR Nelayan Jaring Insang di Desa Panipahan Teluk Pulai Kecamatan Pasir Limau

\begin{tabular}{ccccr}
\multicolumn{2}{c}{ Kapas, Tahun 2021 } & & & Total biaya \\
\hline No & R/C ratio & Penerimaan & Jumlah \\
\hline 1 & RCR & 7.269 .598 & 2.669 .860 & 2,7 \\
2 & RCR & 7.269 .598 & 4.509 .755 & 1,6 \\
\hline
\end{tabular}

Berdasarkan Tabel 6. R/C Ratio setelah semua biaya ditambah dengan upah ABK dan menghasilkan $\mathrm{R} / \mathrm{C}$ ratio yaitu sebesar 1,6 yang artinya setiap modal yang dikeluarkan sebsar Rp 1 akan kembali sebanyak Rp 1,6 Dengan demikian dapat disimpulkan bahwa usaha nelayan jaring insang di Desa Panipahan Teluk Pulai Kecamatan Pasir Limau Kapas dapat dikatakan layak.

\section{Break Event Point (BEP)}

Suatu usaha menguntungkan jika melebihi nilai impas, BEP nelayan jaring insang di Desa Panipahan Teluk Pulai Panipahan Pasir Limau Kapas Dapat dilihat pada Tabel 7.
Dari Tabel 7. BEP Produksi sebesar $203,316 \mathrm{Kg}$, artinya bawa jika total biaya Rp 4.509.755 dan harga penjualan $\mathrm{Rp} 22.181$, maka nelayan jaring insang harus menghasilkan 203,316 Kg untuk balik modal. Keutungan di peroleh nelayan jaring insang jika hasil tangkapan diatas 203,316 Kg.

Berdasarkan Tabel 5. dapat dilihat BEP Harga yaitu sebesar Rp 13.760 yang artinya bahwa dengan total biaya $\mathrm{Rp} 4.509 .755$ dan total produksi $327,742 \mathrm{~kg}$, nelayan jaring insang harus menjual hasil tangkapannya dengan harga $\mathrm{Rp} 13.760$ untuk balik modal. Keuntungan akan di peroleh jika nelayan jaring insang menjual hasil tangkapan diatas Rp 13.760. Untuk lebih jelasnya dapat dilihat pada Gambar 2. Berikut :

Tabel 7. BEP Nelayan Jaring Insang di Desa Panipahan Teluk Pulai Kecamatan Pasir Limau Kapas, Tahun 2021

\begin{tabular}{ccrrrr}
\hline No & \multicolumn{1}{c}{ BEP } & Total biaya & Produksi $(\mathrm{kg})$ & Harga $(\mathrm{Rp})$ & Jumlah \\
\hline 1 & Produksi $(\mathrm{kg})$ & 4.509 .755 & - & 22.181 & 203,316 \\
2 & Harga $(\mathrm{Rp})$ & 4.509 .755 & 327,745 & - & 13.760 \\
\hline
\end{tabular}




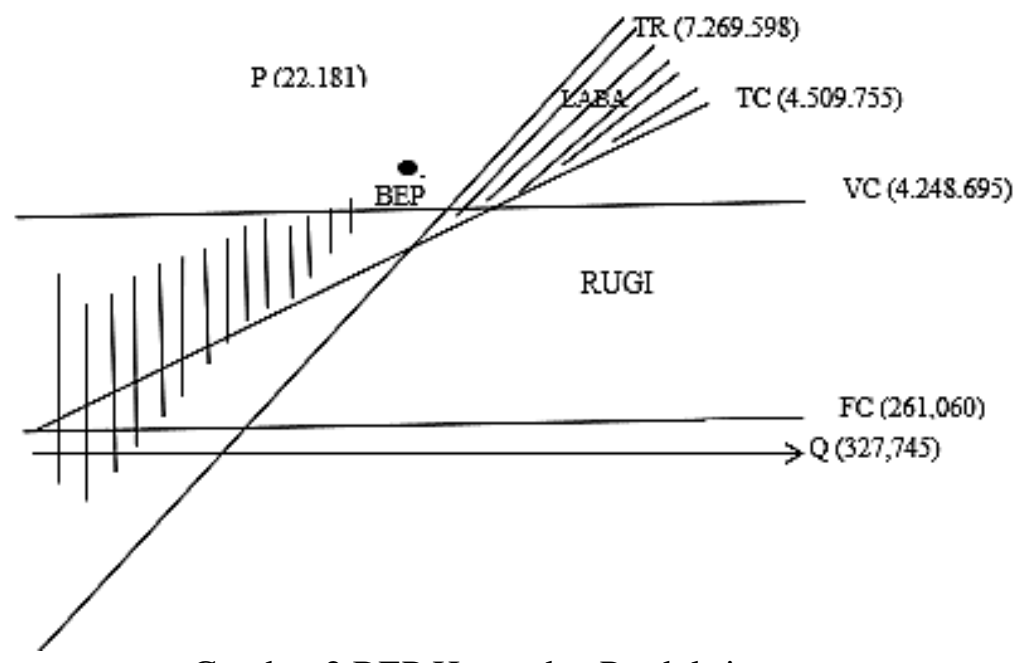

Gambar 2.BEP Harga dan Produksi

Pada gambar 2 dapat dilihat bahwa perpotongan antara garis penjualan dan garis biaya melebihi titik impas, maka usaha dikatakan menguntungkan. Jika dibawah titik impas usaha tersebut mengalami kerugian.

\section{KESIMPULAN}

Berdasarkan hasil penelitian yang telah dilakukan dapat disimpulkan bahwa:

1. Bedasarkan hasil penelitian karakteristik nelayan jaring insang di Desa Panipahan Teluk Pulai Kecamatan Pasir Limau Kapas memiliki umur rata-rata 34,8 tahun yang masih tergolong produktif dan diharapkan dapat meningkatkan pendapatan, tingkat pendidikan 7.4 tahun yaitu hanya sampai di tingkat SMP, Pengalaman berusaha nelayan jaring insang 12.26 tahun sudah termasuk lama untuk meningkatkan pendapatan nelayan jaring insang dan jumlah tanggungan kelurga nelayan jaring insang adalah 3 orang. dan profil usaha dalam bentuk usaha merupakan usaha perseorangan dan skala usaha adalah usaha mikro.

2. Teknologi penangkapan menggunakan kapal motor 5-7 GT, mesin yang layak digunakan juga memiliki kemampuan berlayar dan jaring dengan ukuran 3,5 inc dan panjang 66 bal. Pengoperasian dilakukan dengan jarak tempuh 15 mil kemudian jaring insang disiapkan dan di pisahkan antara pelampung dan pemberat agar dalam pengoperasian mudah dilakukan. Jaring insang tersebut di turunkan kelaut perlahan-lahan dengan cara dihanyutkan yang dilakukan oleh anak buah kapal (ABK). Penurunan jaring di lakukan selama 3 jam baru kemudian jaring tersebut diangkat /tarik kedalam kapal, ikan yang terjerat jaring langsung dibuka/diambil langsung. Ikan yang telah dikumpulkan kemudian dimasukkan kedalam peti es dan kemudian dijual.

3. Biaya yang di keluarkan untuk usaha penangkapan jaring insang sebesar Rp 4.509.755/trip yaitu biaya tetap Rp 261.060, biaya variabel $\mathrm{Rp} 2.408 .800$ dan ABK sebesar Rp 1.839.895. Penerimaan sebesar Rp 7.269.598 dan keuntungan nelayan pemilik/pengoperasi sebesar Rp 2.759.843. dan nelayan usaha jaring insang layak berdasarkan hasil penelitian menunjukan $\mathrm{R} / \mathrm{C}$ ratio sebesar 1,6 , artinya usaha nelayan jaring insang layak untuk di usahakan. BEP produksi nelayan jaring insang adalah $203,316 \mathrm{Kg}$ yang artinya nelayan jaring insang harus menghasilkan 203,316 Kg untuk balik modal dan BEP Harga adalah Rp 13.760 yang artinya nelayan jaring insang harus menjual hasil tangkapannya dengan harga Rp 13.760 untuk balik modal.

\section{DAFTAR PUSTAKA}

Abd. Rahim dan Diah Retno Dwi Hastuti. 2016. Determinan Pendapatan Nelayan Tangkap Tradisional Wilayah Pesisir Barat Kabupaten Barru. Jurnal sosek KP. Fakultas Ekonomi. Universitas Negeri Makassar.

Badan Pusat Statistik Provinsi Riau. 2020. Riau Dalam Angka. BPS Provinsi Riau. Pekanbaru. 
Dauhan,R,L. Andaki,J,A. Lumenta,V. 2014. Analisis Pendapatan dan Sistem Bagi Hasil Nelayan Jaring Insang (Gill Net) Malos 3 di Kelurahan Malalayang Satu Timur Kecamatan Malalayang Kota Manado. Jurnal Ilmiah Agrobisnis Perikanan. Akulturasi. 2 (2) : 189-195.

Dinas Perikanan dan Kelauatan Kabupaten Rokan Hilir. 2020. Laporan Tahunan.Dinas Perikanan dan kelautan Kabupaten Rokan Hilir. Bagansiapi-api.

Direktorat Sumber Daya Ikan. 2006. Definisi dan Klasifikasi Statistik Perikanan Tangkap. Direktorat Sumber Daya Ikan, Direktorat Jenderal Perikanan Tangkap. Jakarta.

Hasiani,Y. Mahreda,E,S. Febrianty,I. 2011. Analisis Pendapatan Usaha Penangkapan Ikan Laut Menggunakan Alat Tangkap Gill Net di Desa Tabanio Kecamatan Takisung Kabupaten Tanah Laut. Jurnal Magister Ilmu Perikanan. Fish Scientiae, 1. (2) : 202-213

Hernanto, F. 1995. Ilmu Usaha Tani. Penebar Swadaya. Jakarta.

Indriantoro, Nur dan supomo, Bambang. 2002. Metode Penelitian Bisnis Untuk Akuntansi \& Manajemen. Edisi 1. Yogyakarta : BPFE.

Kusnadi. (2002). Nelayan Strategi Adaptasi dan Jaringan Sosial. Humaniora, IUtama Press Bandung.

Martasuganda, S. 2002. Teknologi Penangkapan Jaring Insang. Institut Pertanian Bogor. Bogor.

Masyuri.1999. Pasang Surut Usaha Perikanan Laut, Tinjauan Sosial Ekonomi Kenelayanan Jawa dan madura.

Mulyadi.2007. Ekonomi kelautan. Edisi I. PT Raja Grafindo Persada. Jakarta

Rosalinda, Oktaviana dwi.2018. Analisis Pendapatan nelayan Jaring Insang di Kelurahan Cilacap Kecamatan Cilacap Selatan Kabupaten Cilacap.skripsi. Fakultas Pertanian. Universitas Gadjah Mada Yogyakarta.

Sastrawidjaya. 2002. Ciri Komunitas Nelayan. Yogyakarta.
Sastrawidjaya, dkk. 2002. Nelayan Nusantara. Pusat Riset Pengolahan Produk Sosial Ekonomi Kelautan dan Perikanan. Jakarta.

Satria, Arif. 2002. Pengantar Sosiologi Masyarakat Pesisir. Penerbit Pustaka Cisesindo. Jakarta.

Sevilla, Consuelo G, (2017). Research methods. Rex Printing company. Quezoncity.

Siskawati, D., Rizal, A., Prihadi, J.,D., 2016. Analisis Pendapatan Nelayan Jaring Insang Tetap dan Bubu di Kecamatan Membalong Kabupaten Belitung. Jurnal Perikanan Kelautan.VII (2) :9-13.

Soekartawi. 2006. Analisis Usahatani: UI Press, Jakarta.

Sujarno, 2008. Analisis Faktor-Faktor Yang Mempengaruhi Pendapatan Nelayan (Studi Kasus di Kabupaten Langkat). Tesis. Program Pascasarjana. Universitas Sumatera Utara.

Sukirno, 2006. Teori Pengantar Mikro Ekonomi. PT Raja Grafarindo Persada. Jakarta.

Suratiyah, K. 2015, Ilmu Usahatani Edisi Revisi. Penebar Suwadaya. Jakarta

Sutanto, Himawan Arief. 2005. Analisis Efisiensi Alat Tangkap Perikanan Gillnet dan Cantrang (Studi di Kabupaten Pemalang Jawa Tengah). Tesis. Program Pascasarjana Universitas Dipenogoro. Semarang.

Sparre, P and Venema, S.C. 1992. Introduction to tropical fish stock assessment. Part 1.Manual. FAO Fisheries technical paper 306/1. Jakarta

Syarir,M. Nurdiana,A. Mansyur,A.2018. Analisis Pendapatan Nelayan Tangkap Jaring Insang (gillnet) di Desa Lakombulo Kecamatan Bungku Selatan Kabupaten Morowali Provinsi Sulawasi Tengah.

Tuwo, Ambo. 2011. Pengelolaan ekowisata pesisir dan laut. Brilian internasional : Surabaya

Undang-Undang RI No. 31 tahun 2004: Tentang Perikanan

Winardi , 2004, Pengantar Ilmu Ekonomi. Transito, Bandung. 
